\title{
Diagnosis of pulmonary cryptococcosis by ultrasound guided percutaneous aspiration
}

\author{
Li-Na Lee, Pan-Chyr Yang, Sow-Hsong Kuo, Kwen-Tay Luh, Dun-Bing Chang, \\ Chong-Jen Yu
}

Department of Clinical Pathology L-N Lee

S-H Kuo

K-T Luh

Department of Internal Medicine

P-C Yang

D-B Chang

C-J Yu

National Taiwan

University Hospital, 1

Chang-Te Street,

Taipei, Taiwan

Reprint requests to:

Dr Li-Na Lee

Received 4 February 1992

Returned to authors

30 March 1992

Revised version received

15 June 1992

Accepted 25 June 1992

\begin{abstract}
Background Ultrasound is useful for locating thoracic lesions and guiding biopsy procedures. The use of sonographic appearances and ultrasound guided needle aspiration has led to the diagnosis of pulmonary cryptococcosis at this hospital.
\end{abstract}

Methods Six hundred and eight patients who had ultrasound guided lung aspirations were reviewed retrospectively and nine with documented pulmonary cryptococcosis were collected. All patients had nodules or infiltrates on the chest radiograph. The needle aspirates obtained under ultrasound guidance were stained by Riu's or Papanicolaou's method or with India ink, and six were sent for culture. Five patients also underwent bronchoscopy and biopsy.

Results The nine patients had 18 pulmonary lesions, of which 15 were nodules and three infiltrates. Fifteen lesions were detectable by ultrasound, which showed the nodules to be hypoechoic with eccentrically located air echoes. In eight of the nine cases cryptococci were detected after the lung aspirates had been stained with Riu's or Papanicolaou stain or with India ink. In five of the six aspirates sent for fungal culture Cryptococcus neoformans was isolated. The diagnostic yield was higher than that of bronchoscopy. None developed post-aspiration pneumothorax or any evidence of late dissemination.

Conclusions Because they tend to be subpleural pulmonary cryptococcal lesions seem to be identifiable by

Details of the nine patients with pulmonary cryptococcosis

\begin{tabular}{|c|c|c|c|c|}
\hline \multirow[b]{2}{*}{$\begin{array}{l}\text { Patient No/ } \\
\text { sex/age }\end{array}$} & \multirow[b]{2}{*}{$\begin{array}{l}\text { Initial } \\
\text { diagnosis }\end{array}$} & \multicolumn{2}{|l|}{ Biopsy diagnosis } & \multirow{2}{*}{$\begin{array}{l}\text { Source of } \\
\text { positive } \\
\text { culture }\end{array}$} \\
\hline & & $\begin{array}{l}\text { Percutaneous } \\
\text { aspiration }\end{array}$ & Bronchoscopy & \\
\hline $1 / F / 45^{\star}$ & Tuberculosis & Cryptococcosis & Not done & \\
\hline $2 / \mathrm{M} / 50$ & Tuberculosis & Cryptococcosis & Specimen normal & FNA \\
\hline $3 / \mathrm{M} / 40^{+}$ & Cryptococcosis & Cryptococcosis & Specimen normal & FNA, CSF \\
\hline $4 / M / 33$ & Lung cancer & Cryptococcosis & No done & FNA \\
\hline $5 / \mathrm{M} / 39$ & Lung cancer & Cryptococcosis & Not done & \\
\hline $6 / M / 26$ & Lung cancer & Cryptococcosis & Cryptococcosis & Laryngeal swab \\
\hline $7 / \mathbf{M} / 33$ & Pneumonia & $\begin{array}{l}\text { Inadequate } \\
\text { specimen }\end{array}$ & Cryptococcosis & $\begin{array}{l}\text { Bronchial } \\
\text { washing }\end{array}$ \\
\hline $8 / F / 31+$ & Sepsis & Cryptococcosis & Not done & FNA \\
\hline $9 / \mathrm{M} / 73$ & Lung cancer & Cryptococcosis & $\begin{array}{l}\text { Chronic } \\
\text { inflammation }\end{array}$ & FNA \\
\hline
\end{tabular}

*Patient 1 had concurrent diabetes mellitus and hepatic clonorchiasis.

+Patients 3 and 8 had cryptococcal meningitis.

FNA-fine needle percutaneous lung aspirate; $\mathrm{CSF}$-cerebrospinal fluid. ultrasound. Ultrasound guided lung aspiration is an effective, rapid, and safe method for diagnosis.

(Thorax 1993;48:75-78)

The use of ultrasound in the diagnosis and management of pulmonary diseases is increasing. ${ }^{1-6}$ Ultrasound is useful for locating pleural effusions, subpleural solid lesions, apical tumours, and lung tumours with obstructive pneumonitis, and can guide thoracocentesis, percutaneous aspiration, and cutting biopsy. ${ }^{1-6}$ In this paper we report our experience of sonography and ultrasound guided percutaneous aspiration in nine patients with pulmonary cryptococcosis, in whom diagnostic thoracotomy was avoided..$^{7-10}$

\section{Methods}

We performed 608 ultrasound guided lung aspirations from January 1984 to May 1991. Nine of the patients $(1.5 \%)$ were found to have a documented diagnosis of pulmonary cryptococcosis. Their ages ranged from 26 to 73 years and seven were men (table). All had pulmonary nodules or infiltrates on the chest radiograph, cryptococci being observed in or isolated from the lung tissue.

All the patients underwent thoracic ultrasound examination with a linear array or a sector scanner (Aloka SSD-630, Aloka Co, Tokyo) and a $3.5 \mathrm{MHz}$ transducer by an intercostal approach. The images were recorded on polaroid films.

After ultrasonographic assessment informed consent was obtained. We then performed a percutaneous transthoracic aspiration under ultrasound guidance in each patient. We used a linear array probe with a guiding channel with an adjustable angle. A fine aspiration needle (21 or 22 gauge) with an outer sheath and an inner stylet was inserted through the guiding channel into the lesion under direct vision. The aspirates were prepared for Riu's, ${ }^{11}$ India ink, or Papanicolaou staining. In six cases aspirates were also sent for culture of bacteria, fungi, and mycobacteria.

Cryptococcusneoformans was identified according to the standard mycological criteria: growth at $37^{\circ} \mathrm{C}$, the hydrolysis of urea, the failure to assimilate lactose and nitrate, or the observation of budding encapsulated yeasts on the India ink stain. A latex agglutination test was used to detect cryptococcal capsular 

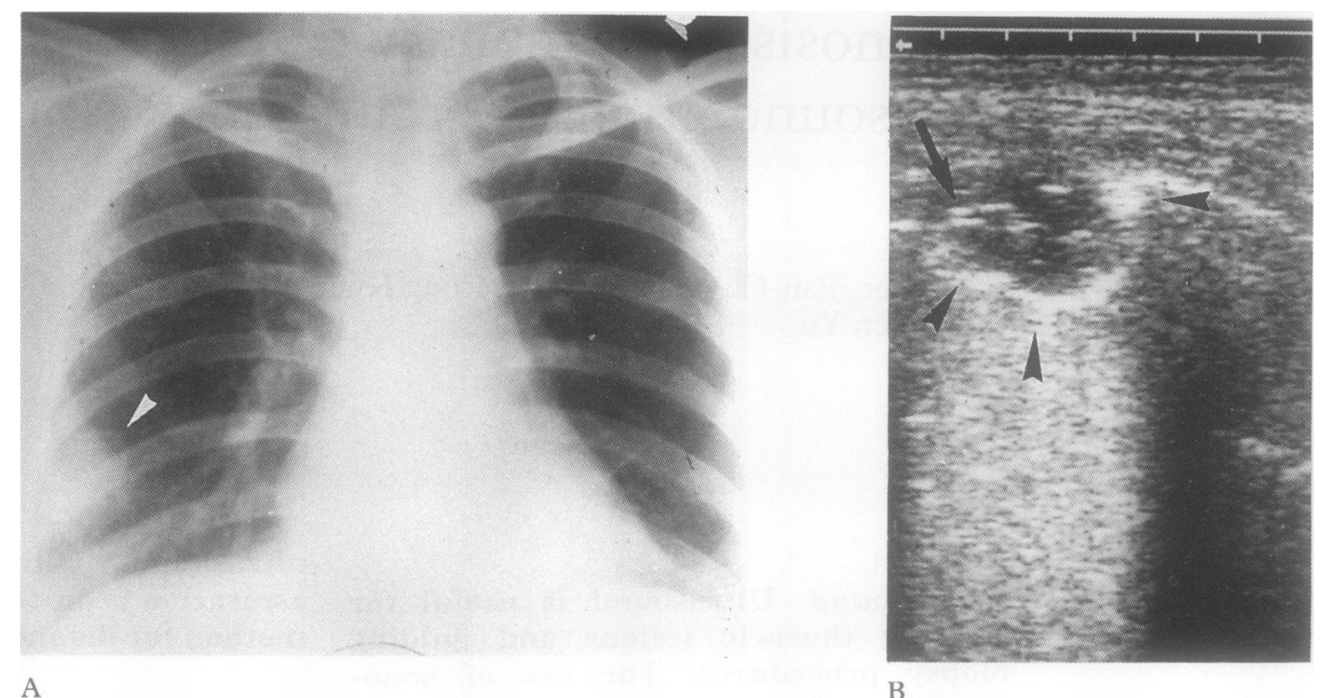

$\mathrm{B}$

Figure 1 A pulmonary cryptococcal nodule: $A$-chest radiograph showing the faint nodular lesion with cavitation; $B$-ultrasonogram showing the subpleural hypoechoic lesion (arrowheads) with air (arrow) mainly in its periphery (scale unit $1 \mathrm{~cm}$ ); C-transthoracic aspirates showing cryptococci (Riu's stain); D-histological section showing lack of a capsule, and normal alveoli (arrowhead) mixed with granulomatous tissue in the margin of the nodule.

antigen $^{12}$ in eight cases. Biopsy via a fibreoptic bronchoscope was performed in five patients and thoracic computed tomography in four.

\section{Results}

RADIOGRAPHIC AND SONOGRAPHIC FINDINGS

Eighteen lesions were found in the nine patients; 15 were nodules with a diameter of $1.5-4.0 \mathrm{~cm}$, and three were segmental or lobar infiltrates. Chest ultrasound detected 15 of these 18 lesions. In the six patients with single or multiple nodules cavities were present in nine of the nodules identified on the plain chest radiograph (fig $1 \mathrm{~A}$ ). Twelve of the 15 nodules were subpleural and were detectable by ultrasound, which showed a hypoechoic background and scanty air pockets, located mainly in the periphery of the nodules (fig 1B). Only one of the three patients with pulmonary infiltrates on the chest radiograph (fig 2A) had a visible cavity. All these infiltrates were accessible by ultrasound, which showed them as hypoechoic areas with irregular margins, and with air bronchograms both in the centre and at the periphery in the case of pneumonic lesions (fig 2B). These appearances were similar to those of consolidation caused by bacteria. In all the lesions the overlying pleura was intact and there were no pleural effusions.

Thoracic computed tomography was performed in four patients (Nos 3, 4, 8, and 9). Cryptococcal nodules appeared as cavitating lesions with either thin or thick irregular walls.

All nine patients underwent percutaneous transthoracic needle aspiration under ultrasound guidance. Eight aspirates showed cryptococci on Riu's, India ink or Papanicolaou stain (fig 1C). The remaining specimen was inadequate for diagnosis. Cryptococcus neoformans was cultured from five of the six aspirates sent for culture of fungi. No other microorganisms were isolated from any of the specimens.
All patients had ultrasonography immediately after lung aspiration. The postaspiration lesions appeared unchanged, which suggested that a pneumothorax had not occurred. Five patients also had chest radiographs within 48 hours. None had a pneumothorax, and none developed extrapulmonary dissemination (follow up period five months to five years).

\section{OTHER DIAGNOSTIC PROCEDURES}

Five patients underwent bronchoscopy with either brushing or transbronchial lung biopsy (table). In three (Nos 2, 3, 9) the bronchoscopy was performed before percutaneous aspiration. In only one patient (No 9) was a lesion visible endoscopically. In this patient the right lower lobe bronchus was almost completely obstructed by swollen and hyperaemic mucosa, but histological examination showed only cells characteristic of chronic inflammation. Cryptococci, however, were found in biopsy specimens from two other patients.

Patient 1 had a thoracotomy, the anterior basal segment of the right lower lobe being resected and the diagnosis of cryptococcosis confirmed. A latex test for serum cryptococcal antigen was performed in eight patients and gave a positive result in five.

\section{TREATMENT AND OUTCOME}

One patient underwent segmental resection of the single nodule. Four were given chemotherapy with amphotericin B or 5-fluorocytosine. Two did not receive any treatment. All patients, however, made a full clinical recovery by six months. Radiographic clearing was complete by 14 months in all patients.

\section{Discussion}

The prevalence of cryptococcosis has been rising, both in normal individuals ${ }^{13-15}$ and in immunocompromised patients. ${ }^{70^{13-18}}$ Diag- 


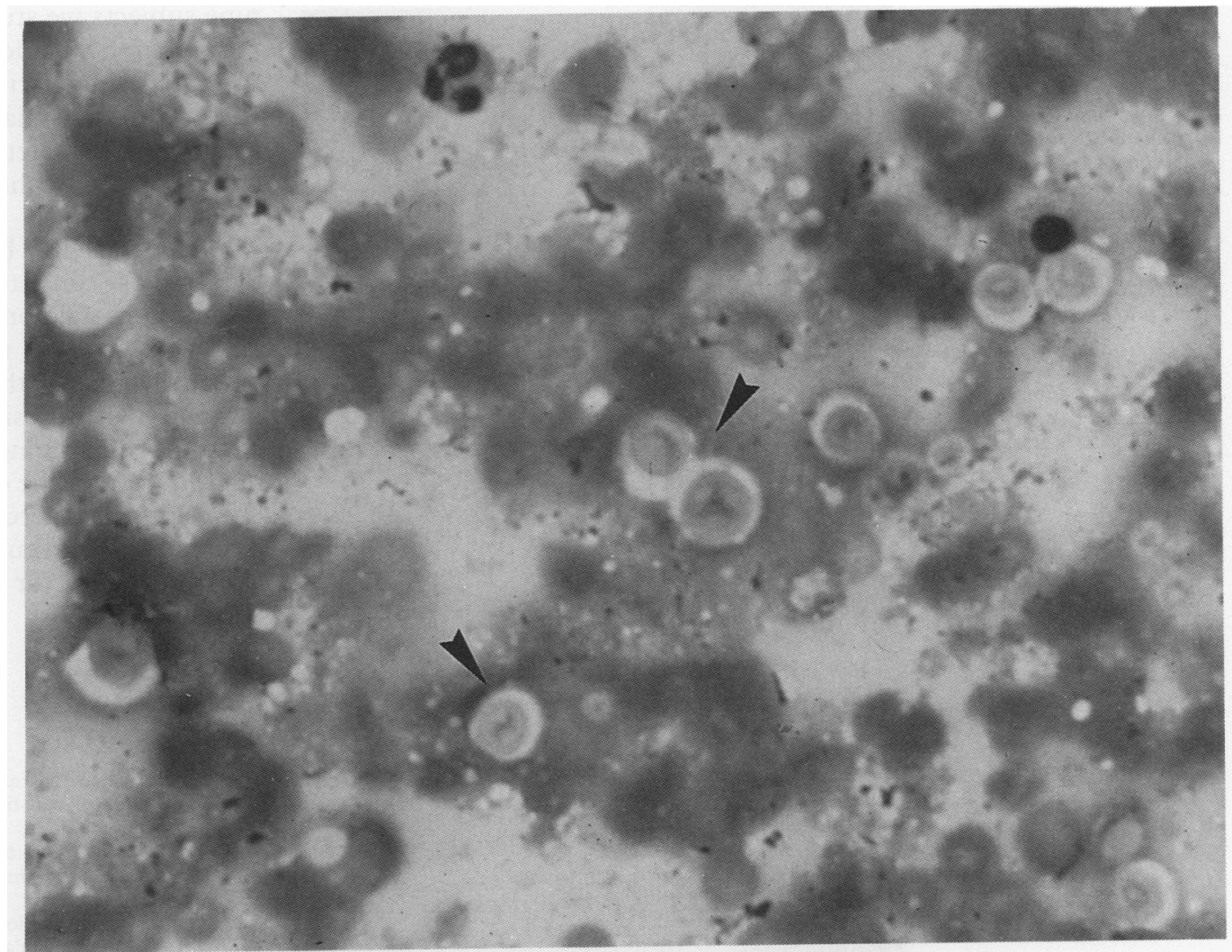

C

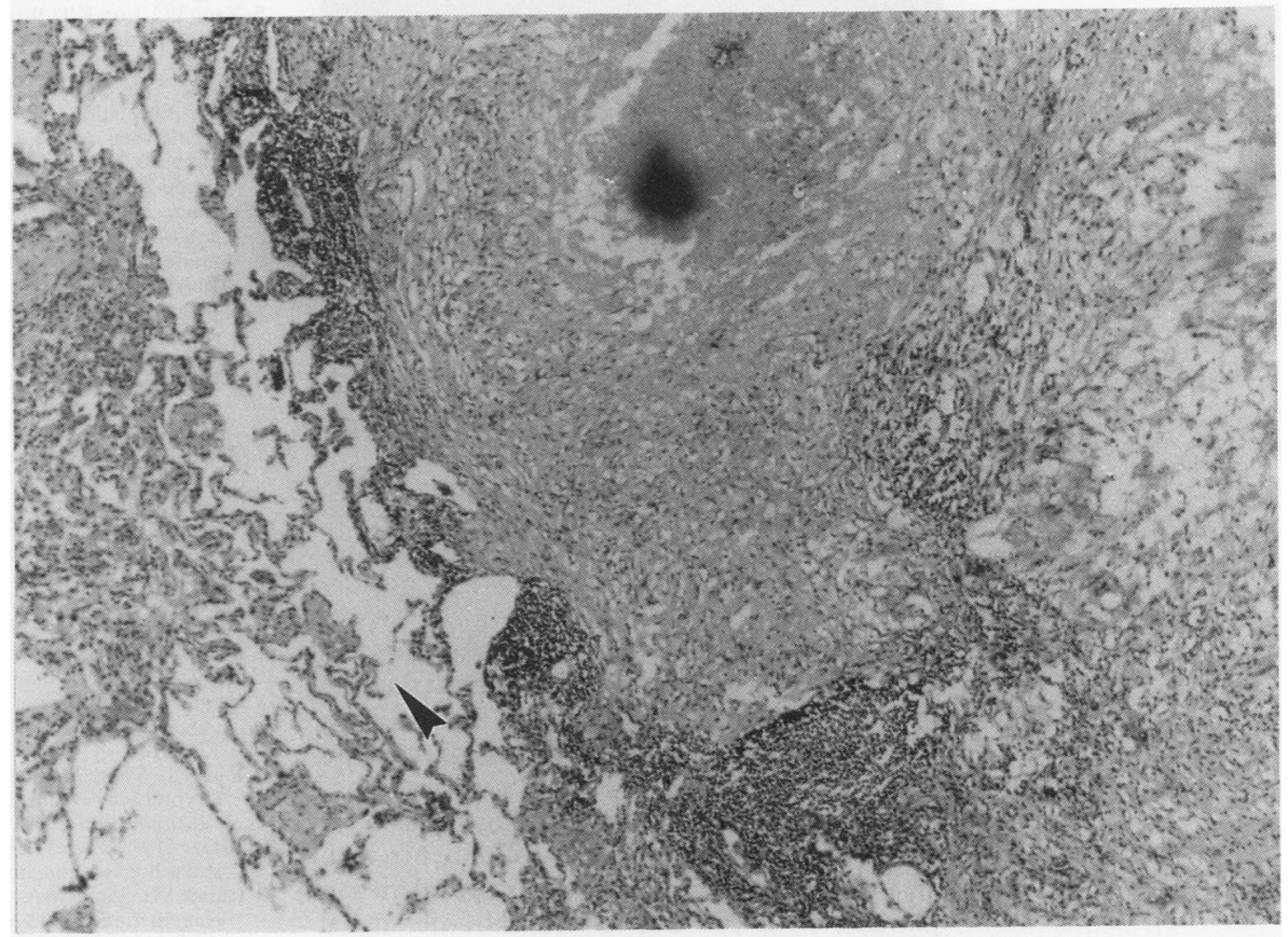

$\mathrm{D}$

nosis of pulmonary cryptococcosis, however, remains difficult. It was considered as the initial diagnosis in only one patient (table), who had concomitant meningitis on admission. In the other eight pulmonary cryptococcosis was not suspected until diagnosed by ultrasound guided aspiration (in seven cases) or bronchoscopic biopsy (in one case).

The diagnostic yield of bronchoscopic biopsy was $56 \%$ in Kerkering's study of 41 patients ${ }^{10}$ compared with $40 \%$ in our study, the low yield being due to the peripheral distribu- 
Figure 2 Pulmonary. cryptococcal pneumonia: $A$-chest radiograph showing opacification of the right lower lobe; $B$ ultrasonogram showing $a$ hypoechoic lesion with an irregular margin

(arrowheads) and with air bronchograms (arrow), a picture similar to that seen in bacterial pneumonia (scale unit $1 \mathrm{~cm})$.

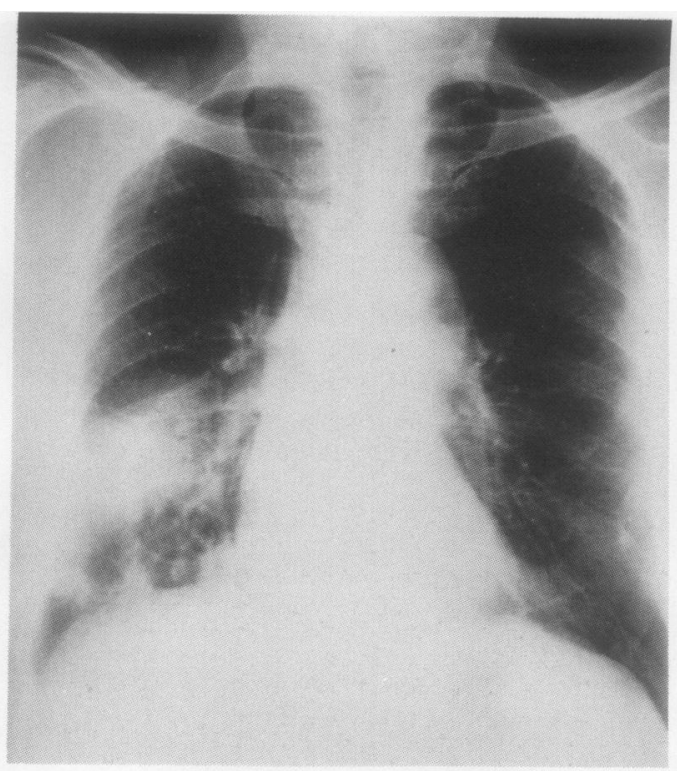

nine subjects we studied. Moreover, the diagnosis can be made rapidly. Aspirates show typical cryptococci after being stained with Riu's stain or India ink, which takes just two minutes. The safety and accuracy of needle aspiration are further increased by ultrasound guidance.

The hypoechoic background shown by sonography is consistent with the histological findings of pulmonary cryptococcal nodules and with mucoid material containing many organisms that fill the alveoli. ${ }^{15} 19$ The air in the periphery of the lesions probably comes either from the intervening normal lung tissue at the margin or from the cavities within the lesion.

In summary, percutaneous needle aspiration under ultrasound guidance is an effective, rapid, and safe method for the diagnosis of pulmonary cryptococcosis.

A.

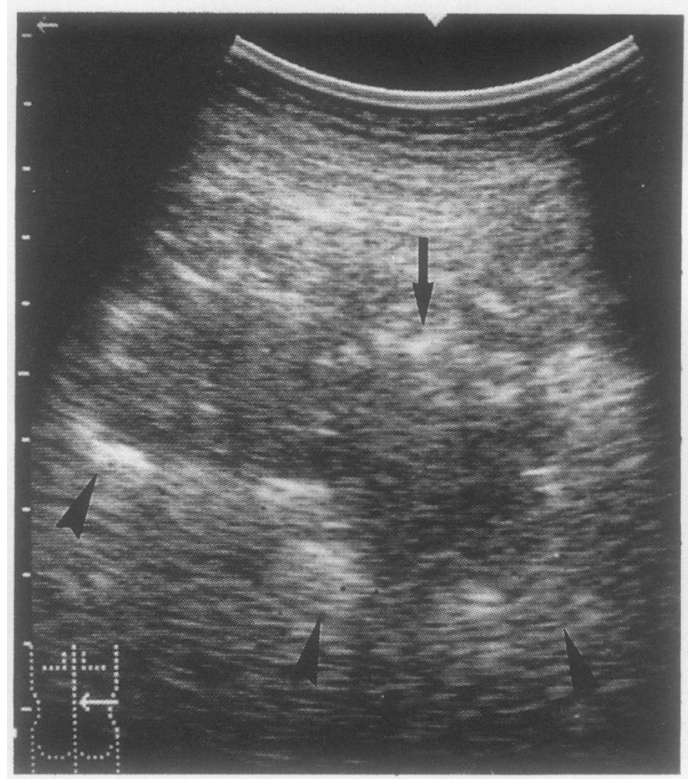

B

tion of the infection. ${ }^{19}$ The value of serological tests is uncertain. Neither complement fixation for cryptococcal antigen nor the indirect fluorescent test for antibody differentiates invasive disease from mere colonisation. ${ }^{20}$ Cryptococcal polysaccharide antigen has been detected in the serum of $90 \%$ of patients with cryptococcal meningitis, ${ }^{21}$ but its prevalence in patients with colonisation or extrameningeal cryptococcosis remains unknown. Thus in most studies open lung biopsy has been the diagnostic procedure of choice. ${ }^{7-10}$

The subpleural location makes these lesions accessible by ultrasound guided needle aspiration. The yield of needle aspiration has been high, ${ }^{10}$ and a diagnosis was made in eight of the
1 Yang PC, Sheu JC, Luh KT, Kuo SH, Yang SP. Clinical application of real-time ultrasonography in pleural and subpleural lesions. Journal of the Formosan Medical Association 1984;83:646-57.

2 Yang PC, Luh KT, Sheu JC, Kuo SH, Yang SP. Peripheral pulmonary lesions: ultrasonography and ultrasonically guided aspiration biopsy. Radiology 1985;155:451-6.

3 Lee LN, Chen CR, Yang GG, Kuo SH, Luh KT. Ultrasonography of thoracic lesions: analysis of 251 cases. Journal of the Formosan Medical Association 1987;86: $838-46$.

4 Yang PC, Lee LN, Luh KT, Kuo SH, Yang SP. Ultrasonography of Pancoast tumor. Chest 1988;94:124-8.

5 Yang PC, Luh KT, Wu HD, Chang DB, Lee LN, Kuo SH, et al. Lung tumors associated with obstructive pneumonitis: US studies. Radiology 1990;174:717-20.

6 Yu CJ, Yang PC, Chang DB, Wu HD, Lee LN, Lee YC, et al. Evaluation of ultrasonically guided biopsies of mediastinal masses. Chest 1991;100:399-405.

7 Campbell GD. Primary pulmonary cryptococcosis. Am Rev Respir Dis 1966;94:236-43.

8 Littman ML. Cryptococcosis (torulosis): current concepts and therapy. Am J Med 1959;27:976-8.

9 Hammerman KJ, Powell KE, Christianson CS, Huggin PM Larsh HW, Vivas JR, et al. Pulmonary cryptococcosis: clinical forms.and treatment. A Center for Disease Control cooperative mycoses study. Am Rev Respir Dis 1973;108:1116-23.

10 Kerkering TM, Duma RJ, Shadomy S. The evolution of pulmonary cryptococcosis. Ann Intern Med 1981;94: 611-6.

11 Lee CH, Lan RS, Tsai YH, Chiang YC, Wang WJ. Riu's stain in the diagnosis of pulmonary cryptococcosis. Chest 1988;93:467-70.

12 Wilson DE, Bennett JE, Bailey JW. Serologic grouping of Cryptococcus neoformans. Proc Soc Exptl Biol Med 1968; 127:820-3.

13 Lewis JL, Rabinovich S. The wide spectrum of cryptococcal infections. Am J Med 1972;53:315-22.

14 Baker RD. The primary pulmonary lymph node complex of cryptococcosis. Am J Clin Pathol 1976;65:83-92.

15 Feigin DS. Pulmonary cryptococcosis: radiologic-pathologic correlates of its three forms. $A J R$ 1983;141: 1263-72.

16 Fan JS, Yang SP, Hsieh WC, Hwang YS, Chen CY. Cryptococcosis in Taiwan. Journal of the Formosan Medical Association 1974;73:313-23.

17 Fraser DW, Ward JI, Ajello L, Plikaytis BD. Aspergillosis and other systemic mycoses. JAMA 1979;242:1631-5.

18 Chuck SL, Sande MA. Infections with Cryptococcus neoformans in the acquired immunodeficiency syndrome. $N$ Engl J Med 1989;321:794-9.

19 Haugen RK, Baker RD. The pulmonary lesions in cryptococcosis with special reference to subpleural nodules Am J Clin Pathol 1954;24:1381-90. forms of pulmonary cryptococcosis. Ann Intern Med 1968;69:117-25.

21 Bennett JE, Bailey JW. Control for rheumatoid factor in the 56:360-5.
20 Tynes B, Mason KN, Jennings AE, Bennett JE. Varian latex test for cryptococcosis. Am J Clin Pathol 1971, 